\title{
Effect of Clinical and Subclinical Hypothyroidism on Fetal Outcomes among Pregnant Women: A Sub-Specialty Department Experience
}

\author{
Farzana Sharmin ${ }^{1}$, Mahfuja Asma², Khandaker Shehneela Tasnim³ , Afzal Momin', \\ Shimul Akhter ${ }^{5}$, Tripti Rani Das ${ }^{6}$, Firoza Begum? \\ ${ }^{1}$ Assistant Professor, Department of Obstetrics \& Gynecology, Bangabandhu Sheikh Mujib Medical University, Dhaka, Bangladesh; \\ ${ }^{2}$ Consultant, Department of Obstetrics and Gynecology, Attachment- Department of Fetomaternal Medicine, Bangabandhu Sheikh \\ Mujib Medical University, Dhaka, Bangladesh; ${ }^{3}$ Consultant, Department of Obstetrics and Gynecology, Shaheed Suhrawardy \\ Medical College Hospital, Dhaka, Bangladesh; ${ }^{4}$ Associate Professor, Department of Clinical Neurology, National Institute of \\ Neurosciences \& Hospital, Dhaka, Bangladesh; ${ }^{5}$ Assistant Professor, Department of Obstetrics and Gynecology, Monowara \\ Shikder Medical College, Shariatpur, Bangladesh; ${ }^{6}$ Chairman and Professor, Department of Obstetrics and Gynecology, \\ Bangabandhu Sheikh Mujib Medical University, Dhaka, Bangladesh; ${ }^{7}$ Professor and Ex-Chairman, Department of \\ Fetomaternal Medicine, Bangabandhu Sheikh Mujib Medical University, Dhaka, Bangladesh
}

[Received on: 22 November 2020; Accepted on: 12 December 2020; Published: 1 January 2021]

\begin{abstract}
Background: Hypothyroidism can effect on the fetal outcomes during pregnancy. Objective: The purpose of the present study was to compare the effects of clical and subclinical hypothyroidism on fetal outcomes among pregnant women. Methodology: This cohort study was conducted in the Feto-Maternal Department of Bangabandhu Sheikh Mujib Medical University, Dhaka, Bangladesh from a period of 6 months dated from September 2019 to February 2020. All cases of the clinical and sub-clinical hypothyroid pregnant women admitted in this department. Fetal outcomes of clinical and sub-clinical hypothyroid pregnant women during delivery were recorded. Findings of the cases recorded carefully. Result: A total number of 75 patients were recruited for this study who were divided in to two group designated as group I or sub clinical hypothyroidism and group II or clinical hypothyroidism. Fetal distress was $22(51.1 \%)$ cases in group I and $9(33.3 \%)$ cases in group II. The fetal outcome of the study patients had observed that $8(27.6 \%)$ and $12(80.0 \%)$ of the baby had low $(<2.5 \mathrm{~kg})$ birth weight in group I and group II' respectively. In group I most $(62.1 \%)$ of the baby APGAR score was $>7$ and $11(73.3 \%)$ cases had $<6$ APGAR score at 1 st minute. Majority of the study patients had $>7$ APGAR score at $5 \mathrm{~min}$ in both groups which was 25(86.2\%) and 12(80.0\%) in group I and group II respectively. Conclusion: In conclusion there is a significant difference found in overt and sub-clinical hypothyroidism considering fetal stress, IUD and prematurity. [Journal of National Institute of Neurosciences Bangladesh, January 2021;7(1): 29-32]
\end{abstract}

Keywords: : Effect; clinical; subclinical hypothyroidism; fetal outcomes; pregnant women

Correspondence: Dr. Farzana Sharmin, Assistant Professor, Department of Obstetrics \& Gynecology, Bangabandhu Sheikh Mujib Medical University, Dhaka, Bangladesh; Email: shuvrabsmmu@yahoo.com; Cell no.: +8801781618201

Conflict of interest: There is no financial conflict of interest relevant to this paper to disclose.

Funding agency: This research project was not funded by any group or any institution.

Contribution to authors: Sharmin F, Asma M, Tasnim KS contributed from the protocol preparation, data collection up to report writing. Manuscript writing was performed by Sharmin F; Begum F, Momin A, Akhter S have revised the manuscript.

How to cite this article: Sharmin F, Asma M, Tasnim KS, Begum F, Momin A, Akhter S. Effect of Overt and Subclinical Hypothyroidism on Fetal Outcomes among Pregnant Women. J Natl Inst Neurosci Bangladesh, 2021;7(1): 29-32

Copyright: (C2021. Sharmin et al. Published by Journal of National Institute of Neurosciences Bangladesh. This article is published under the Creative Commons CC BY-NC License (https://creativecommons.org/licenses/by-nc/4.0/). This license permits use, distribution and reproduction in any medium, provided the original work is properly cited, and is not used for commercial purposes.

\section{Introduction}

Thyroid disorders constitute one of the most common endocrine disorders seen in pregnancy ${ }^{1}$. Globally overt hypothyroidism has been reported 1 in 1000 to 1 in 1600 deliveries and subclinical hypothyroidism in 0.19 to $2.5 \%$ of pregnancy ${ }^{2}$. Women with hypothyroidism have relatively increased, fertility, miscarriage rates and carry an increased risk for obstetric and fetal complications. The main obstetric complications are anaemia, preeclampsia, cardiac dysfunction, placental abruption and postpartum hemorrhage. Fetal complications include prematurity, low-birth weight (LBW), fetal distress in 
labor, fetal death, perinatal death and congenital hypothyroidism ${ }^{3}$.

Pregnancy may affect the course of thyroid disorders and, conversely, thyroid diseases may affect the course of pregnancy ${ }^{4}$. Moreover, thyroid disorders and their management may affect both the pregnant woman and the developing fetus. Finally, pregnant women may be under the care of multiple health care professionals, including obstetricians, nurse midwives, family practitioners, endocrinologists and/or internists. There is a lack of agreement regarding the correct reference ranges to use, whether thyroid-stimulating hormone (TSH) or free thyroxin (FT4) levels are the most important determinants of normality, what the impact of inadequate or excess treatment might be (on the mother or the baby) and whether correct treatment can improve neonatal outcome ${ }^{5}$. These difficulties are often further compounded by practical issues such as suboptimal pre-pregnancy control, late gestation at booking, poor compliance, and malabsorption related to pregnancy-induced vomiting or to the use of iron or calcium supplements. Recommendations for management are generally based on expert opinion, and even protocols from leading groups are not based on strong evidence and do not concur ${ }^{6}$.

It is generally accepted that a proportion of women with hypothyroidism need to increase their dose of thyroxin during pregnancy, but it is unclear how these dose changes should be decided ${ }^{7}$. While some studies suggest that decisions should be based on thyroid function tests (TFTs) at the booking visit and during pregnancy and have reported that many women would not need an increment, others have proposed a global increase in the thyroxin dose as soon as pregnancy is confirmed. There are concerns about this as not only may it be unnecessary for many women but also fetal exposure to excess T4 and T3 may be associated with miscarriage and low birth weight $^{8}$. The purpose of the present study was to compare the effects of overt and subclinical hypothyroidism on fetal outcomes among pregnant women.

\section{Methodology}

This was a prospective cohort study. This study was conducted in the Feto-Maternal Department of Bangabandhu Sheikh Mujib Medical University, Dhaka, Bangladesh. The study was conducted over a period of 6 months, dated from September 2019 to February 2020. All cases of the clinical \& sub-clinical hypothyroid pregnant women admitted in this department. Recently diagnosed hypothyroid pregnant women (either during the study on period, or within the 6 previous months of study period) for whom, data related to the diagnosis is available, admitted patients who were diagnosed as clinical \& subclinical hypothyroidism during antenatal checkup were included in this study. Subject presenting a major risk of not being able to follow-up until the next TSH level (moving, problems encountered during another study, pathology affecting the vital prognosis in the short-term), all contraindications to Levothyrox or Thyroxin intolerable patients were excluded from this study. This study was approved by Local Ethical Committee of BSMMU. Prior to data collection a questionnaire was designed for this study by reviewing all of the available questionnaire of previous studies along with the help and critical analysis of the Guide of this study. After taking informed oral (if need written) consent from the women, attending Feto-Maternal Department of BSMMU, relevant data were collected by the investigator herself. Findings of the cases recorded carefully. Data were collected in a pre-designed form. All data -vas analyzed by using computer based SPSS version 16.0 (Statistical package for social sciences, Chicago) program. Statistical analysis was performed, categorical variables was presented in the form of frequency and percentage and analysis of association was made using Chi-square test of significance. Quantitative data was presented in the form of mean and standard deviation. Comparison of means made by using student's t-test. A p-value less than 0.05 was considered statistically significant.

\section{Results}

This study was conducted among 75 patients and they were divided into two age groups. Maximum $62.79 \%$ number was found in the age group of 25 to 44 years in group I and $65.62 \%$ cases in group II. Significant $(p<0.05)$ age difference was observed in Chi square test between the groups (Table 1).

Table 1: Age Distribution of the Study Patients ( $\mathrm{n}=75)$

\begin{tabular}{lccc}
\hline Age Group & Group I & Group II & P Value \\
\hline 15 to 24 Years & $16(37.2 \%)$ & $11(34.37 \%)$ & \\
25 to 44 Years & $27(62.79 \%)$ & $21(65.62 \%)$ & 0.800 \\
Total & $\mathbf{4 3 ( 1 0 0 . 0 \% )}$ & $\mathbf{3 2 ( 1 0 0 . 0 \% )}$ & \\
\hline
\end{tabular}

Group I: Sub clinical hypothyroidism; Group II: Overt hypothyroidism; Chi-square test was performed to see the level of significant.

The fetal complications were observed more in group I than that of group II. 3 abortion was found in group II. Therefore, total number of group II was 29 cases. Fetal 
distress was 22(51\%) cases in group I and 9(31\%) cases in group II. Prematurity was three times more in group I $(39.5 \%)$ than in group II (13.8\%). PPH, Uterine rupture, abortion and IUD observed only in group 11 patients. Statistically significant $(\mathrm{p}<0.05)$ difference was observed in all complications except Uterine rupture $(\mathrm{p}>0.05)$ (Table 2).

Table 2: Distribution of the study Patients according to Complications during Delivery $(\mathrm{n}=57)$

\begin{tabular}{|c|c|c|c|}
\hline Fetal Complications & Group I & Group II & P Value \\
\hline Fetal distress & $22(51.0 \%)$ & $9(31.0 \%)$ & \\
\hline IUD & $0(0.0 \%)$ & $5(17.24 \%)$ & 0.0019 \\
\hline Prematurity & $17(39.5 \%)$ & $4(13.8 \%)$ & \\
\hline
\end{tabular}

Group I: Sub clinical hypothyroidism; Group II: Overt hypothyroidism; Chi-square test was performed to see the level of significant.

In this study 3 cases were presented with abortion and 5 cases were given intrauterine death. Therefore the total number of group II was 24 cases. The fetal outcome of the study patients had observed that $8(27.6 \%)$ and $12(80.0 \%)$ of the baby had low $(<2.5 \mathrm{~kg})$ birth weight in group I and group II' respectively. In group I most $(62.1 \%)$ of the b APGAR score was $>711(73.3 \%)$ had less than 6 APGAR score at 1st minute. Majority of the study patients had $>7$ APGAR score at $5 \mathrm{~min}$ in both groups which was $25(86.2 \%)$ and $12(80.0 \%)$ in group I and group II respectively. Only $4(13.8 \%)$ in group I and $3(20.0 \%)$ in group II newborn were admitted in NICU. No hypothyroidism was identified in cord blood. Birth weight and APGAR score at 1st minute were statistically significant $(\mathrm{p}<0.05)$, but others were not significant $(\mathrm{p}>0.05)$. Perinatal death occurred in 1 baby after 5 days admission in NICU due to respiratory distress and complications of prematurity (Table 3 ).

\section{Discussion}

Thyroid disease is particularly common in women of child-bearing age 9 . As a result, it is no surprise that thyroid disease may complicate the course of pregnancy. It is estimated that $2.5 \%$ of all pregnant women have some degree of hypothyroidism ${ }^{10}$.

Conversely, in hypothyroid women with adequate treatment, the frequency of abortions was minimal and pregnancies were in general carried to term without complications $^{11}$. This prospective cohot study was carried out with an aim to compare the effects of Clinical and Subclinical hypothyroidism on fetal outcome among pregnant women. A total of 50 admitted patients who were diagnosed as clinical and sub clinical hypothyroidism during antenatal check were included in the study, in the Feto-Maternal Department of BSMMU during September 2019 to February 2020.

In this present study it was observed that $30.2 \%$ and $75 \%$ babies had low $(<2.5 \mathrm{~kg})$ birth weight in sub clinical hypothyroidism patients and clinical hypothyroidism patients respectively. Sharmeen et al ${ }^{12}$ observed that $27.6 \%$ and $80 / 0 \%$ babies had low birth weight $(<2.5 \mathrm{~kg})$ in subclinical hypothyrism and $80 \%$ in clinical hypothyroidism respectively. In sub clinical hypothyroidism patients $41.86 \%$ babies and $37.5 \%$ cases babies of clinical hypothyroidism had APGAR score $<6$ at 1 st minute. APGAR score was $86.2 \%$ cases and $80.0 \%$ cases in sub clinical hypothyroidism patients and clinical hypothyroidism patients respectively. Only $9.3 \%$ in sub clinical hypothyroidism patients and $33.3 \%$ in clinical hypothyroidism patient's newborn were admitted in NICU. Low birth weight and NICU admission were significantly $(\mathrm{p}<0.05)$ higher in clinical hypothyroidism patients, but others were not significant

Table 3: Distribution of the Study Patients According to Fetal Outcome $(n=67)$

\begin{tabular}{|c|c|c|c|c|}
\hline \multirow[t]{2}{*}{ Variables } & \multicolumn{2}{|c|}{ Groups } & \multirow[t]{2}{*}{ Total } & \multirow[t]{2}{*}{ P value } \\
\hline & Group I & Group II & & \\
\hline \multicolumn{5}{|l|}{ Birth Weight (kg) } \\
\hline - $\quad<2.5 \mathrm{~kg}$ & $13(30.2 \%)$ & $18(75 \%)$ & $31(\%)$ & \multirow{2}{*}{0.0004} \\
\hline$\geq 2.5 \mathrm{~kg}$ & $30(69.7 \%)$ & $6(25 \%)$ & $36(\%)$ & \\
\hline \multicolumn{5}{|c|}{ APGAR Score at $1 \mathrm{~min}$} \\
\hline - $\quad<6$ & $18(41.86 \%)$ & $9(37.5 \%)$ & $27(\%)$ & \multirow{2}{*}{0.726} \\
\hline - $\quad>7$ & $25(58.1 \%)$ & $15(62.5 \%)$ & $40(\%)$ & \\
\hline \multicolumn{5}{|c|}{ APGAR score at 5 min } \\
\hline - $\quad<6$ & $4(9.3 \%)$ & $8(33.3 \%)$ & $12(17.3 \%)$ & \multirow{2}{*}{0.0139} \\
\hline$\cdot \quad>7$ & $39(90.6 \%)$ & $16(66.6 \%)$ & $55(82.7 \%)$ & \\
\hline \multicolumn{5}{|c|}{ Admission in NICU } \\
\hline - $\quad$ Yes & $4(9.3 \%)$ & $8(33.3 \%)$ & $12(17.3 \%)$ & \multirow{2}{*}{0.0139} \\
\hline No & $39(90.6 \%)$ & $16(66.6 \%)$ & $55(82.7 \%)$ & \\
\hline
\end{tabular}

Group I: Sub clinical hypothyroidism; Group II: Overt hypothyroidism; Chi-square test was performed to see the level of significant. 
( $>0.05$ ). Perinatal death occurs in 1 baby after 5 days' admission in NICU due to respiratory distress and complications of prematurity. Miller et $\mathrm{al}^{13}$ observed that low birth weight was $11.1 \%$ in their whole study patients with hypothyroidism, out of which $7.1 \%$ cases and $12.9 \%$ cases in sub clinical hypothyroidism and clinical hypothyroidism respectively. Poppe and Glinoer ${ }^{14}$ reported in their study that fetal complications include prematurity, low-birth weight (LBW), fetal distress in labor, fetal death, perinatal death and congenital hypothyroidis ${ }^{15-17}$. Cord TSH and neonatal day-3 TSH screening was performed in limited cases of Vaidya et $\mathrm{al}^{17}$ study and no significant association was found between them and maternal TSH.

\section{Conclusion}

In conclusion fetal distress is found to be more in patients with subclinical hypothyroidism than clinical hypothyroidism. There is also significant difference found in clinical and sub-clinical hypothyroidism considering IUD and prematurity. Furthermore, fetal distress, IUD, Low birth weight, APGAR score $<6$ were significantly higher in patients with clinical hypothyroidism. Further large scale study should be carried out country.

\section{References}

1. Abalovich M, Amino N, Barbour LA, Cobin RH, De Groot LJ, Glinoer D, et al. Management of thyroid dysfunction during pregnancy and postpartum: an Endocrine Society Clinical Practice Guideline. The Journal of Clinical Endocrinology \& Metabolism. 2007;92(8 supplement):s1-7

2. Current diagnosis and treatment, Alan H. Decherney, Lauren Nathan, T murphy Goodwin, Nerilaufer, 2004, 10th edi p388

3. Dunn JT. Choice of therapy in young adults with hyperthyroidism \& Graves' disease in Pregnancy. Ann Intern Med 1984;100:891-893

4. Kothari A, Girling J. Hypothyroidism in pregnancy: pre-pregnancy thyroid status influences gestational thyroxine requirements. BJOG: An International Journal of Obstetrics \& Gynaecology. 2008;115(13):1704-8

5. Krassas GH, 2005 The male and female reproductive system in Hypothyrodism. In: Braverman L.F. Uriger RD. editors. Werner \& Ingbar's the Thyroid A Fundamental and Clinical Text. Lippincott Williams \& Wilkins. 9th ed. Philadelphia. 824-827

6. Leung AS, Millar LK, Koonings PP, Montoro MA, Mestman JH. Perinatal outcome in hypothyroid pregnancies. Obstetrics and gynecology. 1993;81(3):349-53

7. Matalon S, Sheiner E, Levy A, Mazor M, Wiznitzer A. Relationship of treated maternal hypothyroidism and perinatal outcome. The Journal of reproductive medicine. 2006;51(1):59-63 8. Sahu MT, Das V, Mittal S, Agarwal A, Sahu M. Overt and subclinical thyroid dysfunction among Indian pregnant women and its effect on maternal and fetal outcome. Archives of gynecology and obstetrics. 2010;281(2):215-20

9. Mestman JH, Goodwin TM, Montoro MM. Thyroid disorders of pregnancy. Endocrinology and metabolism clinics of North America. 1995;24(1):41-71

10. Mestman JH. Hyperthyroidism in pregnancy. Best Practice \& Research Clinical Endocrinology \& Metabolism. 2004;18(2):267-88

11. Miah SM, Islam R, Sardar S, Uddin M, Sharmin S. Outcome of pregnancy in treated hypothyroidism. Bangladesh J. Nucl Med. 2009;12(2):84-9

12. Sharmeen M, Shamsunnahar PA, Laila TR,Chowdhury SB.Overt and subclinical hypothyroidism among Bangladeshi Pregnant women and its effect on Fetomaternal outcome.Bangladesh Med res Counc Bull 2014;40:52-57

13. Millar LK, Wing DA, Leung AS, Koonings PP, Montoro MN, Mestman JH. Low birth weight and preeclampsia in pregnancies complicated by hyperthyroidism. Obstetrics \& Gynecology. 1994;84(6):946-9

14. Poppe K, Glinoer D. Thyroid autoimmunity and hypothyroidism before and during pregnancy. Human reproduction update. 2003;9(2):149-61

15. Rashid M, Rashid MH. Obstetric management of thyroid disease. Obstetrical \& gynecological survey. 2007;62(10):680-8

16. Tan TO, Cheng YW, Caughey AB. Are women who are treated for hypothyroidism at risk for pregnancy complications? American Journal of Obstetrics and Gynecology. 2006;194(5):e1-3

17. Vaidya B, Anthony S, Bilous M, Shields B, Drury J, Hutchison S, Bilous R. Detection of thyroid dysfunction in early pregnancy: universal screening or targeted high-risk case finding? The Journal of Clinical Endocrinology \& Metabolism. 2007;92(1):203-7 